\title{
Store robberies for tobacco products: Perceived causes and potential solutions
}

\author{
Marewa Glover, * Robin Shepherd, * Hamed Nazari, ${ }^{\dagger}$ and Kyro Selket*
}

\begin{abstract}
Robberies of New Zealand convenience stores for tobacco products spiked between 2016 and 2017. According to media reports, many robberies involved the use of weapons and resulted in injury to retailers. We conducted a content analysis of all online media articles containing commentary about these robberies, published between 2014 and 2019 , to identify the perceived causes of the increase in robberies for tobacco and remedies implemented or demanded. The commentators in the articles were categorized into three groups of stakeholders: elites, grassroots, and interest groups. Overall, there was a mismatch between perceiving the primary cause to be socially and economically determined and suggesting solutions that were mostly situational shop level changes or tertiary prevention strategies, such as more and harsher policing. A further mismatch was that existing policing policy was not adapted to balance the perverse consequences of the tobacco excise tax increases. Early commentators tended to deflect blame away from their own sector. Later commentary converged to agree that the high tobacco excise tax was a critical causal factor.
\end{abstract}

Key Words Tax; convenience stores; crime prevention; policing.

\section{INTRODUCTION}

Tobacco smoking is estimated to cause 7 million preventable deaths annually worldwide (World Health Organization (WHO), 2018). The WHO Framework Convention on Tobacco Control (FCTC) promotes an extensive range of interventions to reduce harmful tobacco use (e.g., raise the price of cigarettes via tax, ban advertising).

With its novel 1990 Smoke-Free Environments Act (SFEA), New Zealand (NZ) became a model for the FCTC. Over subsequent years, NZ extended its SFEA several times, adding ever greater restrictions on smoking behaviour and the advertising, sale, and distribution of tobacco products. Significantly, tobacco excise tax regularly increased many times more than the required annual Consumer Price Index (CPI) adjustments. As a result, tobacco in NZ is among the highest priced in the Organization for Economic Co-operation and Development (OECD). As of January 2021, a pack of 20 average brand cigarettes cost NZ\$32 (US\$21). The Customs and Excise Tax law has also introduced several other restrictions, such as reducing how much tobacco people can grow for their own use, banning the import of tobacco leaf for personal use, and reducing how much duty-free tobacco people can bring into the country for their own use.

In many other countries that haveimplemented a similarly comprehensive program of restrictions on access to tobacco, including high taxation, cheaper tobacco cigarettes have been smuggled across state and country borders. For example, Australia has surpassed NZ in how restrictive its tobacco control policies are, and they have a higher level of taxation. Australia has close neighbours, a vast sparsely populated coastline, and a growing market in smuggled illicit tobacco (Lauchs \& Keane, 2017). By contrast, NZ is a few hours by plane, or a few days by sea, from its nearest neighbours, has a coast only half the length of Australia's, and a well-resourced and vigilant border control force.

In 2015, the media began to report with greater frequency that $\mathrm{NZ}$ convenience stores were being robbed for tobacco products. There are three reasons why this was shocking to the NZ public. Firstly, the stores most frequently targeted were what is known in NZ as the "dairy"-a small, usually family-owned corner store set on its own or in a small suburban-based block of small stores serving the local residential area (see Glover et al., 2021, for a fuller description).

Supplemental material for this article available online at journalcswb.ca

Correspondence to: Dr. Marewa Glover, Centre of Research Excellence: Indigenous Sovereignty and Smoking, PO Box 89186, Torbay, Auckland, 0742, New Zealand. E-mail: m.glover@coreiss.com

To cite: Glover, M., Shepherd R., Nazari, H., \& Selket, K. (2021). Store robberies for tobacco products: Perceived causes and potential solutions. Journal of Community Safety and Well-Being, 6(4), 191-196. https://doi.org/10.35502/jcswb.210

@ Author(s) 2021. Open Access. This work is distributed under the Creative Commons BY-NC-ND license. For commercial re-use, please contact sales@sgpublishing.ca.

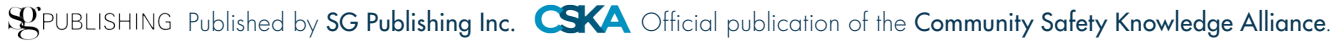


Briefly, these are iconic stores that have historically been safe community places needing little security. Secondly, many of the thieves brandished weapons, bashed shop staff, and caused property damage. Vehicles, many stolen, were driven into shopfronts in ram raid style. Thirdly, the frequency of tobacco robbery reports increased month on month, causing concern to mount. In a previous study, we outlined the characteristics of the robberies reported during the period 2009-2018 (Glover et al., 2021). That study did not investigate the cause of the robberies, which is a focus of this study. To the best of our knowledge, little research has been done globally on robberies of convenience stores for tobacco.

This study analyzed media articles published online during the period 2009-2019 to identify perceived causes of the tobacco robberies and potential solutions offered by three types of commentators: elites, grassroots, and interest groups.

\section{METHOD}

\section{Study Design}

Given the lack of previous research on this topic, an exploratory qualitative content analysis design was chosen.

\section{Data Sources and Search Strategy}

In January 2019, the search engines Google and Bing were used to systematically search for online news articles published in NZ media from 2009 to January 2019, using 20 key words such as tobacco, cigarette, burglary, robbery, dairy, shop, and store. Eighteen NZ news media websites were also searched using these keywords, including seven national sites, eight regional-focused sites, and three ethnic-focused sites. The search criteria were modelled on criteria used in our previous study on the characteristics of the convenience store robberies (Glover et al., 2021).

Articles were excluded if they were blogs, social media posts, letters to the editor, or editorials, or if the article contained no commentary on the causes of, or preventive solutions for, the robberies. Also excluded were articles discussing robberies in which tobacco was targeted or stolen from non-store settings, such as from a residential house, bar, or club. Articles discussing smuggled tobacco were excluded. Articles only repeating previously reported comments by the same commentator were excluded.

Data extracted from each article included the date of the article, author (or media outlet if no author was identified), and website link to the article. These data were entered into an Excel spreadsheet. Each article was assigned a unique identifying number (ID). A research assistant independently checked every record for accuracy of the metadata against the linked article. An electronic database of the data is available upon request. The article ID is attached to each quote included in Supplemental Tables 1 and 2.

Perceived causes and suggested solutions were coded and grouped to form themes and subthemes. Implemented or called-for solutions were coded using Lab's (2019) crime prevention strategy framework, which categorizes strategies as primary, secondary, or tertiary. Primary prevention strategies target social determinants of crime. Secondary prevention strategies target situational factors that will make acts of crime more difficult to execute. Tertiary prevention strategies attempt to change people's intent to commit crime through punishment and rehabilitation (Lab, 2019). The commentators were categorized using Goode and Ben-Yehuda's (1994) stakeholder types: elites, grassroots, and interest groups.

\section{Data Analysis}

Coding was initially deductive in that content was identified as relevant to perception of causes or solutions of tobaccorelated robberies. The extracted content within each category was then inductively coded to group content with the same topic to form subthemes.

The commentator of each unique comment was classified using Goode and Ben-Yehuda's (1994) division of society into the elites-those in power with the most influence over policy, the grassroots-people with the least power to influence policy, and the interest groups-people representing organizations, agencies, and groups or associations. This categorization of stakeholders was used to investigate whether the perceptions of the causes of the robberies differed by stakeholder group and whether they had favoured solutions.

People in power, or closely linked to those in power via their financial or academic influence (the elites) typically determine the narrative driving the direction of government policy. They may include academics, politicians, journalists, police in high-ranking positions, and government officials. Grassroots people are those in the community being threatened and harmed, such as the shop owners. Other grassroots stakeholders include offenders, community bystanders, shop customers, and members of the public. Interest groups have vested interests in, and advocate for, the welfare of the grassroots individuals and communities, which may be commercial or pastoral. Their interests may be ideological, ethnic, or cultural. In this study, interest groups are groups of people who were not members of the elite and are somewhat remote from what was happening to the grassroots victims of the robberies. Examples are associations representing the interests of particular ethnic groups, tobacco companies, and the retail sector.

The articles were read and coded independently by a research assistant and a senior researcher. Their coding was compared, and differences were discussed until a consensus was reached. A third researcher from a different discipline (criminology) was engaged to independently review the coding. Discussions led to some quotes being recoded.

\section{RESULTS}

Two hundred and thirteen (213) media articles were identified for review against the inclusion criteria. Excluded articles were repeats or they discussed robberies, but not tobacco. No eligible articles dated earlier than 2014 were found. A total of 102 articles remained for analysis.

Within the category of perceived causes, three themes and a number of subthemes were identified. A summary of the themes, subthemes, and exemplar quotes from the three commentator groups is presented in Supplemental Table 1. Quotes are presented in chronological order within each cell.

\section{Perceived Causes of Robberies for Tobacco}

Three themes of perceived causes of robberies were identified: 1) Social contextual factors including economic and social determinants, drug or alcohol use, and youth; 
2) Regulation including the tobacco tax increases and inadequate enforcement and penalty; and 3) Black marketthe unintended outcome of the interaction of themes 1 and 2.

These themes and subthemes are organized into the causal model presented in Figure 1. The assumptions implicit in this model are deduced from the overall commentary, which characterized perceived causes as chronological. That is, commentators said the robberies were caused by a "complex mix" of existent factors that interrelated to create an environment that is composed of economic and social determinants of behaviour (e.g., social inequality, poverty, unemployment, lack of parental control) and contextual demographic features (e.g., youth, drug and alcohol use).

Introduced into that environment are regulatory interventions or levers of behaviour: a tobacco excise tax to encourage people to stop smoking and, quite separately, a crime prevention policy that determines the focus of police efforts and the deterrent strength of enforcement and punishment.

The robberies of convenience stores for tobacco are a black market activity, but the black market was also a perceived cause of the robberies. That is, commentators thought the tax on tobacco created a "very significant demand" for cheaper and illicit black market tobacco and made tobacco into an alternative currency that could be used to trade on the black market. For example, commentators said the tax had caused tobacco to be "treated like currency" and that it had placed retailers "in the centre of a drug war, where tobacco is like gold." One commentator said that "the government was partly responsible for the tobacco black market."

Regulations governing policing and punishments, as intended, mitigate black market activity. Most comments on policing, enforcement, and punishments believed these were inadequate. An interest group commentator believed that many robberies were unreported because the "retailers know nothing is going to be done [by the police]."

\section{Perceived Causes by Stakeholder Group}

In early commentaries, the elites offered an eclectic range of potential factors as perceived causes, including tobacco tax increases and economic and social determinants. Then, in 2018 and January 2019, they altered their determination of the causes to focus on the tax increases and the black market. Grassroots commentators predominantly perceived that inadequate policing and enforcement, and lenient penalties,

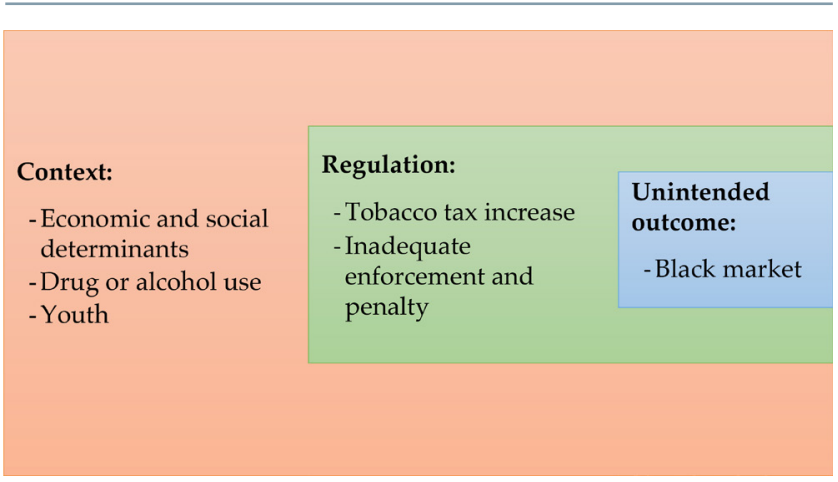

FIGURE 1 Causal model: Perceived causes of robberies enabled the robberies to occur. They did not change this view over the period of this study. In 2016, interest group commentators echoed grassroots commentators in that they blamed inadequate enforcement and lenient penalties for the occurrence of the robberies. Over time, the views of the interest group commentators became more aligned with the elites' view that tobacco tax increases and the black market were causal. In a ty pical comment, an interest group commentator perceived the black market to be "where the whole cycle is starting."

\section{Potential Solutions of Robberies for Tobacco}

There were three pre-determined themes-primary, secondary, and tertiary prevention strategies_-and thirteen inductively identified subthemes for perceived solutions of robberies, as shown in Figure 2. Exemplar quotes sorted by theme from the three commentator groups are presented in Supplemental Table 2. Quotes are presented in chronological order within each cell.

In terms of primary prevention strategies, the commentators believed that economic and social determinants, such as poverty and unemployment, need to be addressed by the government. Especially, "bridging the gap between the haves and the have-nots was critical" (elite). The government needs to stop increasing the tax on tobacco. An academic (elite) analyzed the situation as "This is a way of taking money from the poor so you can give with one hand and you take with the other." A retailer (grassroots) commented, "they're getting all the revenue, and not using it to help people who get robbed every day." Additional primary prevention strategies included: involving the community more in disapproving of and reporting crime to the police. "Neighbours need to get together in order to protect their communities... The more people that help out, the more crime will decrease" (grassroots). Some elites wanted the sale of tobacco banned or more heavily restricted. One commentator said, "[dairy owners] wouldn't be a target if business operators refused to stock cigarettes in the first place." Grassroots commentators called for the government to implement more effective crime prevention programs. As one retailer said, the "government should take some responsibility and not lay it solely on small business owners to safeguard themselves from possible armed offenders."

The secondary prevention strategies emphasized situational factors, such as increasing and improving security technology or selling alternatives to cigarettes, especially e-cigarettes, instead of continuing to sell smoking tobacco products. Shifting sales of tobacco cigarettes to alcohol stores, which already have a higher level of security, was suggested by several elite commentators. In June 2017, the Police Minister (elite) announced a co-funded initiative to provide "high volume interior alarms, DNA spray, fog cannons and time safes for cash and storage of cigarettes" for high-risk stores. Cigarette vending machines that dispense one pack at a time were called for by several commentators in the elite and interest group stakeholder groups. Related situational changes suggested included improving store layout. This was mostly focused on getting greater visibility into stores (e.g., "opening up the dairies to public view would be the answer" (interest group commentator)) and making items of higher value harder to access. One suggested situational change, 

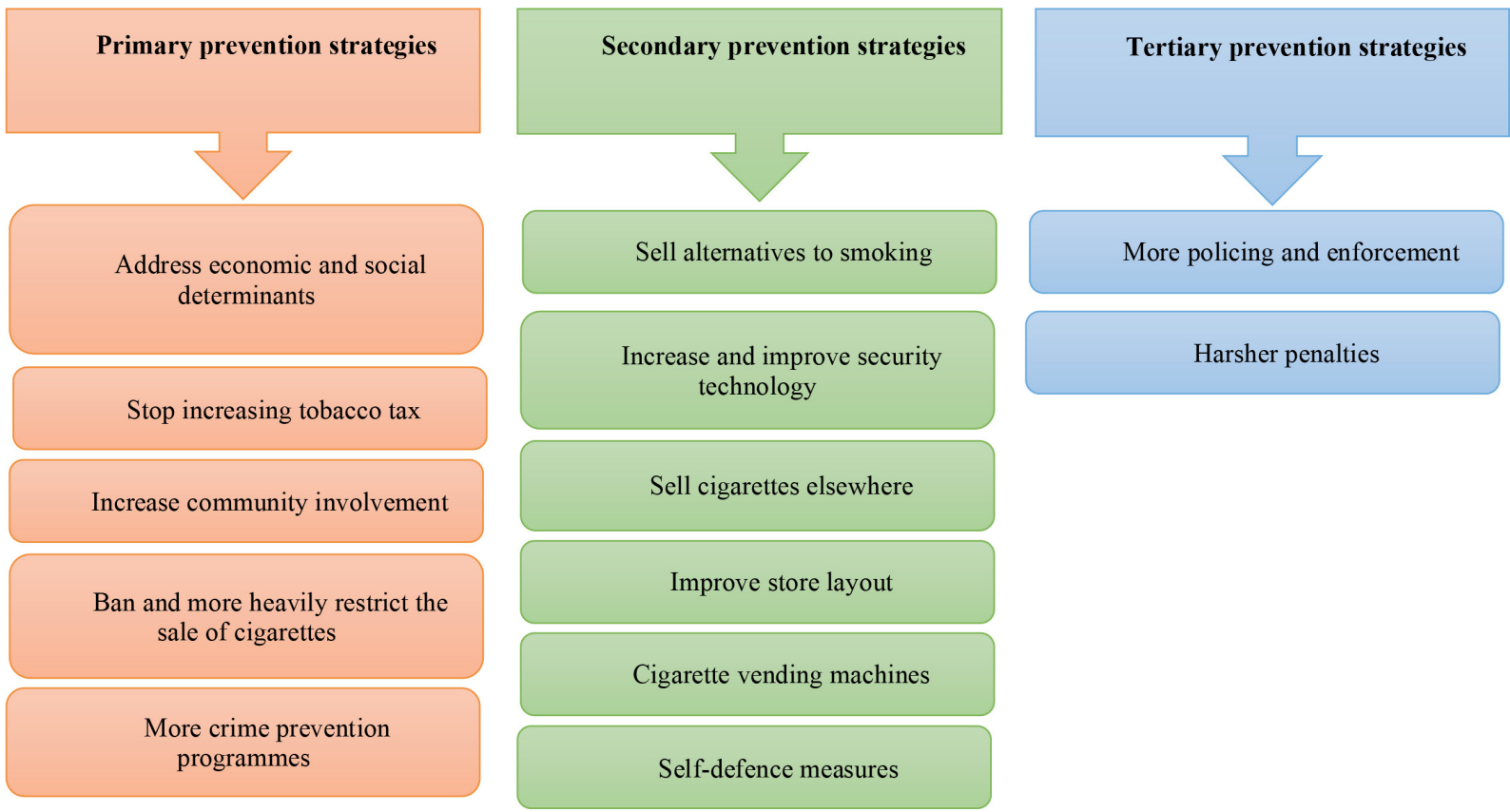

FIGURE 2 Suggested solutions for robberies of tobacco

highlighting the level of grassroots despair and frustration, was that retailers should be able to resort to self-defence. A representative from an association of store owners (interest group) said "We're not saying that guns should be actually used, but dairy owners are sick and tired and fed up."

There were two tertiary solutions suggested. Members of all three stakeholder groups called for harsher penalties for offenders. For example, a retailer (grassroots) suggested "those who committed the crimes needed to be in jail for at least six months or one year." More policing and enforcement was a popular solution. A crime prevention group (interest group) commentator recommended, "This issue is so serious... We need more police, and we need to see the enforcement."

\section{Potential Solutions by Stakeholder Group}

Over time, the elite commentators consistently suggested that their favoured solutions to stopping the robberies were to stop increasing the tobacco tax and increase situational crime prevention interventions, such as improving security technology and store layout.

Early in the commentaries, grassroots commentators, principally store retailers, were calling for improved security technologies and to stop the tobacco tax increases. By 2018, grassroots commentators were expressing a lot more frustration with what they perceived as inadequate policing. Specifically, they were calling for more policing and enforcement, harsher penalties for offenders, and the right to defend themselves.

In the early reporting on the phenomenon, interest group commentators had similar attitudes to those of the elites, believing that robberies could be deterred by increased situational prevention strategies. By the end of the period of the study they had aligned their views with the grassroots commentators' call for intensified tertiary prevention strategies, such as more policing and enforcement and harsher penalties.

\section{DISCUSSION}

Overall, there was a mismatch between the perceived causes and suggested solutions. In NZ, the robberies of convenience stores for tobacco products were perceived to be caused by an interrelated mix of factors. The demographics of NZ (i.e., a youthful population) and economic and social determinants (e.g., employment and income inequity by age) were seen to create and elevate susceptibility to participate in crime. The tobacco tax increases were perceived to be a significant driver for increased demand for cheaper black market tobacco. An additional perverse effect of the tobacco tax policy was the creation of a highly valuable in-demand commodity (i.e., stolen cigarettes) that could be used as an alternative currency on the black market for other products, such as drugs.

The existing level of policing and enforcement was perceived to be inadequate for the surge in this class of crime. Additionally, NZ's moderate to light penalties, depending on age of the offender - the younger the offender, the lighter the punishment-was perceived to be an insufficient deterrent.

The resulting causal model, though based on commentary, suggested that reduction and prevention of the robberies would need to be addressed via primary crime prevention strategies-those that target social determinants of crime. However, the majority of suggested solutions were store-level strategies, such as improving security technology, installing cigarette vending machines and adjusting store layout. These are secondary prevention strategies aimed at making it harder to commit the crime, but they do nothing to impact primary determinants of criminal behaviour. The commentators also 
believed that harsher penalties and more police presence (tertiary strategies) would stop the robberies.

In addition, a mismatch between regulatory policies was identified. Tobacco excise tax increases were repeated annually for more than a decade, despite disproportionately high smoking rates among the lowest socioeconomic groups. Smoking prevalence rates are $25.9 \%$ in quintile 5 and $16.5 \%$ in quintile 4 (most deprived neighbourhood residential areas), compared with a smoking prevalence of just $6 \%$ among quintile 1 (least deprived area) (Ministry of Health, 2020). That is, the price of tobacco was raised beyond the economic means of a large proportion of people who smoked (Ernst and Young, 2018). They did not stop smoking, as was the intention of the tax increases. Instead, an extraordinary demand for black market tobacco was created.

Like the mismatch between the perceived causes of the robberies for tobacco and the potential solutions, public health has not effectively alleviated the economic and social determinants that drive smoking. Specifically, demand for tobacco has not decreased at a pace consistent with the interventions intended to restrict supply. The stop-smoking support on offer was either not acceptable to this population, or the availability and efficacy of stop-smoking support was insufficient.

When demand exceeds supply, the search for substitutes or illicit sources of tobacco will naturally increase. In most other countries, cross-border smuggling is the principal route for black market tobacco. New Zealand's great geographic distance from other countries and efficient border control means that the black market sought out internal sources of supply for tobacco, that is thefts from local stores.

The use of Goode and Ben-Yehuda's (1994) stakeholder types enabled the identification of some differences in opinion between the elites, grassroots, and interest groups. The elites tended to deflect blame onto criminals, drug users, wayward youth, and economic and social determinants. Elites who were members of the opposition party in parliament blamed the incumbent government for poor policy decisions, such as increasing the tobacco tax. Grassroots stakeholders (principally retailers) also blamed government policies for the robbery phenomenon. They cited a range of policy issuesthe tax increases, inadequate policing, poor enforcement, and a justice system that is too lenient on offenders. Interest groups generally supported the grassroots stakeholders, blaming the government for increasing tobacco taxes and creating a black market. Meanwhile, some of the tobacco industry stakeholders believed that retailers should take responsibility to protect themselves and create a safer environment in their shops.

In general, the three groups of stakeholders had different and sometimes contradictory points of view regarding the solutions. Elites blamed "society" and they wanted society to solve its own problems. They suggested more community involvement, improving store layout, and that cigarettes should be sold elsewhere. Contrary to that view point, grassroots wanted more government intervention, including more crime prevention programs and harsher penalties. If the government would not do more to protect them, grassroots retailers wanted to be allowed to carry guns to protect themselves. Interest group stakeholders wanted more policing and enforcement via more government intervention, but they also supported improving store layout and installing security technologies.

Overall, the secondary and tertiary prevention solutions were given more emphasis by the stakeholders than the primary prevention solutions. Whilst more vigilant enforcement and harsher penalties can reduce black market activity (Kulick et al., 2016), it increases the risk of violence-related harms and incarceration.

\section{Strengths and Limitations}

One strength of this study was its unique focus. At the time of this study, we did not find any research on robberies of convenience stores for tobacco that discussed the perceived causes and solutions.

There are, however, several limitations. This was exploratory research constrained by the limits of analyzing online news media article content and not social media. Exclusion of opinion pieces and editorials was a limitation since they also contain commentary. However, the analysis of the commentaries by stakeholder type was a strength that would have been undermined if anonymous commentaries were included. Link rot (when web links destruct or disappear with time (Koehler, 2004)) may have reduced access to the number of articles that were actually published. However, all eligible articles, rather than just a sample, were included in the analysis, which was a strength.

Another limitation was that the journalists appeared to approach the same stakeholders repeatedly for comment. One commentator was the spokesperson for a few different interest groups. This can result in one person's perspective appearing to be dominant and shared.

An important limitation of this study was that not one article cited a consumer (a person who smokes tobacco) or an offender. Any attempts to determine the actual, versus the perceived, causes of the robberies should attempt to learn from these groups.

\section{CONCLUSION}

In Australia and New Zealand, reduction in smoking prevalence has stalled over the last decade. This is despite provision of free counselling, heavily subsidized (often free) cessation medications, mass media campaigns, dramatic increases in tobacco taxes (more than in all other countries), and extensive environmental bans on smoking (Callison \& Kaestner, 2014; Gallet \& List, 2003). The tobacco tax increases have increased demand for cheaper cigarettes on the black market. Inadequate policing and enforcement, as a mediator, has failed to offset the perceived rewards gained by offenders.

To reduce perverse effects, such as robberies for tobacco products, the police should have greater involvement in public health policy analysis and decisions (Crofts \& Thomas, 2017). The police should be involved at early stages of conceptualizing public health interventions for social behaviours they usually a re charged with preventing or reducing - these include violence, theft, and trade in illicit goods. The police should also be involved when public health calls for repressive regulation in an attempt to prohibit behaviours that represent a risk to health but in other ways cause no harms that fall within the remit of the police. 
The failure of public health to consider potential perverse effects of continuing to increase the excise tax on tobacco led to considerable harm for the retail staff who were injured, community safety (Glover et al., 2021), the lower socioeconomic groups who have higher smoking rates, and minority groups at higher risk of incarceration.

In NZ, the tobacco tax increases continued annually for over a decade until 2020. Largely because of the convenience store tobacco robbery phenomenon, the government did not renew the schedule of tax increases from 1 January 2021. Before tobacco excise tax increases are reinstituted, the causes and solutions of robberies for tobacco identified in this study should be considered. That is, the prevalence of smoking among the lower socioeconomic groups needs to be balanced against the attractiveness and efficacy of support to stop smoking. Recent regulation supporting adults who smoke in their efforts to make a change to risk-reduced alternatives to smoking, particularly vaping, may contribute to shifting the current imbalance that leaves people smoking despite the price hikes. Instead of improving community well-being, tobacco control policies that seek to appropriate police as a repressive resource to stop people smoking divert police from their historically established and expected role in society and risk increasing injury, magnifying disparities, and worsening economic and social determinants of smoking. Diversion of police from, for instance, preventing violent crimes to policing tobacco smoking creates an opportunity cost that could undermine not only the police's achievement of their usual goals but other public health goals, such as preventing injury and protecting mental health.

\section{ACKNOWLEDGEMENTS}

We are grateful to Professor Dennis Viehland for editing assistance. This study was funded with a grant (FSFW COE1-009) from the Foundation for a Smoke-Free World, Inc. ("FSFW"), a US non-profit 501(c)(3) private foundation with a mission to end smoking in this generation. This study is, under the terms of the grant agreement with FSFW, editorially independent of FSFW. The contents, selection and presentation of facts, as well as any opinions expressed herein, are the sole responsibility of the authors and under no circumstances should they be regarded as reflecting the positions of FSFW.

\section{CONFLICT OF INTEREST DISCLOSURES}

The authors have no conflicts of interest to declare.

\section{AUTHOR AFFILIATIONS}

*Centre of Research Excellence: Indigenous Sovereignty \& Smoking, Auckland, New Zealand; 'Independent researcher, Hamilton, New Zealand.
SUPPLEMENTAL MATERIAL

Supplemental information linked to the online version of the paper at journalcswb.ca:

- Table S1

- Table S2

\section{REFERENCES}

Callison, K., \& Kaestner, R. (2014). Do higher tobacco taxes reduce adult smoking? New evidence of the effect of recent cigarette tax increases on adult smoking. Economic Inquiry, 52(1), 155-172. https://doi. org/10.1111/ecin.12027

Crofts, N., \& Thomas, S. (2017). Law enforcement and public health: Finding common ground and global solutions to disparities in health and access to criminal justice. Journal of Community Safety and Well-Being, 2(3), 74-75. https://doi.org/10.35502/icswb.56

Ernst \& Young. (2018). Evaluation of the tobacco excise increases as a contributor to Smokefree 2025. Final report. Wellington, New Zealand. https://www.health.govt.nz/system/files/documents/ pages/evaluation-tobacco-excise-increases-final-27-nov2018.pdf

Gallet, C. A., \& List, J. A. (2003). Cigarette demand: A meta-analysis of elasticities. Health Economics, 12(10), 821-835. https://doi.org/ 10.1002/hec.765

Glover, M., Shepherd, R., Selket, K., \& Paramanathen, S. K. (2021). Price hikes, crime fad or political football? What caused a spike in store robberies for cigarettes in New Zealand: analysis of news reports (2009-2018). Safer Communities, 20131, 172-188. https://doi. org/10.1108/SC-09-2020-0034

Goode, E., \& Ben-Yehuda, N. (1994). Moral panics: Culture, politics, and social construction. Annual Review of Sociology, 20(1), 149-171. https://doi.org/10.1146/annurev.so.20.080194.001053

Koehler, W. (2004). A longitudinal study of Web pages continued: A consideration of document persistence. Information Research, 9(2). Available from: http://informationr.net/ir/9-2/paper174.htm|

Kulick, J., Prieger, J., \& Kleiman, M. A. (2016). Unintended consequences of cigarette prohibition, regulation, and taxation. International Journal of Law, Crime and Justice, 46, 69-85. https://doi.org/10.1016/ i.ijlci.2016.03.002

Lab, S. (2019). Crime prevention: Approaches, practices, and evaluations. Routledge.

Lauchs, M., \& Keane, R. (2017). An analysis of the Australian illicit tobacco market. Journal of Financial Crime, 24(1), 35-47. https://doi.org/ 10.1108/JFC-10-2015-0056

Ministry of Health. (2020, November). New Zealand Health Survey Annual Data Explorer. Ministry of Health. https://minhealthnz.shinyapps.io/ nz-health-survey-2019-20-annual-data-explorer/_w_0475e0a8/\#!/

World Health Organization. (2018). WHO global report on trends in prevalence of tobacco smoking 2000-2025. World Health Organization. https://www.who.int/publications/i/item/who-globalreport-on-trends-in-prevalence-of-tobacco-use-2000-2025-third-edition 